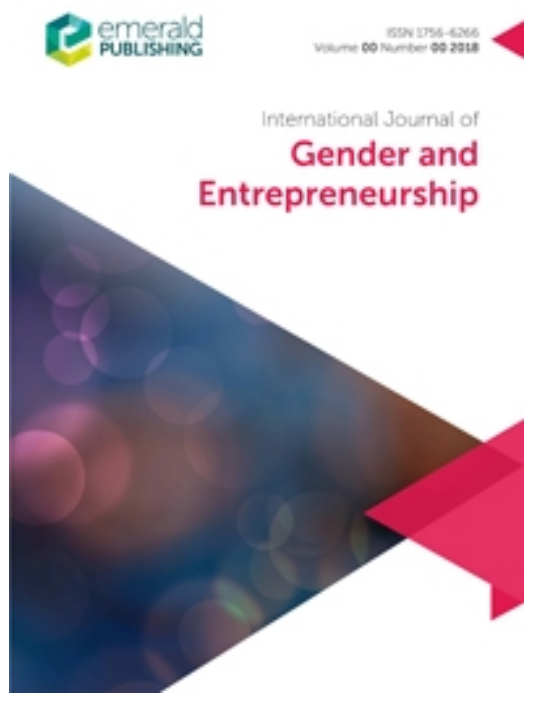

Insights on the glass ceiling for immigrant women entrepreneurs in the technology sector

\begin{tabular}{|r|l|}
\hline Journal: & International Journal of Gender and Entrepreneurship \\
\hline Manuscript ID & IJGE-10-2020-0169.R3 \\
\hline Manuscript Type: & Research Paper \\
\hline Keywords: & Womens entrepreneurship, Innovation, Self-employment, Strategy \\
\hline \multicolumn{2}{|l}{} \\
\end{tabular}

SCHOLARONE
Manuscripts 


\title{
Insights on the glass ceiling for immigrant women entrepreneurs in the technology sector
}

\begin{abstract}
This systematic literature review explores the barriers faced by immigrant women entrepreneurs (WEs) in the technology sector and their strategic responses. Findings indicate immigrant status further escalates the human, financial, and network disadvantages faced by women who want to start a technology-based venture. This paper contributes to the literature by categorizing the barriers and strategies on a three-by-two matrix reflecting the origins of the barrier or strategy (taking place at the individual, firm, or institutional level) versus the type of the barrier or strategy (arising from being an immigrant woman and being a woman in the technology sector). After highlighting the dearth of studies in the literature about the complex phenomenon of immigrant WEs in the technology sector, the paper points out several neglected themes for future research.
\end{abstract}

\section{Introduction}

Entrepreneurship is a critical factor in economic growth (Acs et al. 2017). Novel technologies developed by entrepreneurs, particularly complex and innovative ones, significantly contribute to economies worldwide (Mason and Brown, 2014). Technology ventures seek innovations to all of their stakeholders in the ecosystem (Dautzenberg, 2012). The development of new products and services and the creation of new and innovative business models help build robust technology ventures, resulting in wage gains, increased productivity, and further capital accumulation (Hart and Acs, 2011).

Despite the importance of innovative and technology-based firms, many countries have underutilized their human resources by restricting women entrepreneurs (WEs) in technology ventures (Marlow and McAdam, 2012; Cetindamar and Beyhan, 2019). Although the number of women in the technology sector has increased, WEs still lead only $1.7 \%$ of ventures in the information, communication and technology sector (GEM, 2019).

The entrepreneurship literature generally fails to accommodate a feminist lens (Ahl and Marlow, 2012) since most existing studies focus on the performance of women-owned firms in the technology sector relative to those owned by men (Marlow and Patton, 2005; Sharafizad and Coetzer, 2017). The majority of studies do not investigate the social context that could help understand why there are fewer WEs than male entrepreneurs; instead, existing studies are mainly driven by the assumption that WEs should be like men entrepreneurs (Marlow and Swail, 2014). 
The participation of women in entrepreneurship is rising (GEM, 2019). However, women-owned start-ups usually operate in traditionally female-typed sectors (i.e., retail and service sectors), with lower participation in male-typed sectors (i.e., construction and manufacturing industries) (GERA, 2016). Few explanations have been offered for this difference. One such explanation is the presence of a glass ceiling, a term popularized in 1986 by a reporter for the Wall Street Journal to describe "the invisible barrier that blocks women from the most senior positions in corporate America" (Mattis, 2004, p. 158). Mattis (20024) also confirms a glass ceiling that acts as a barrier to women's career advancement.

Similar to the analogy of the glass ceiling, Boyd (1984) suggests layers of disadvantages for immigrant WEs. Following Mattis (2004), the critical barriers faced by immigrant WEs could be termed the double glass ceiling, which indicates the double disadvantages they face by being a woman and an immigrant. Boyd (1984) describes this double disadvantage as follows:

[S]ex adds another dimension to the stratification of immigrants within the workplace and within the larger society. In addition to the status of being a migrant, immigrant women experience additional difficulties in the labor force as women. Overall, the position of immigrant women in the labor force can be understood as reflecting the combined impact of sex and birthplace or the "double negative" effect. (1984, p. 10)

Immigrants are classified as individuals born outside the host country (Kalu and Okafor, 2020; Haseki et al., 2020). The UN (2019) reports that there are 272 million international migrants worldwide, with an increase of almost 100 million from 2010 to 2019. Studies also show that increased numbers of immigrant WEs have been observed (Dheer, 2018). As Rametse et al. (2018) point out, an immigrant's likelihood of founding a venture is greater than that of a native, especially in OECD countries. This is due to the numerous barriers they face in the ordinary working world, such as a lack of language fluency or poor acceptance of home country education and work experience, which pushes them to opt for entrepreneurship as a career (Mestres, 2010, Rametse et al. 2018). Also, the same study has shown that nearly $20 \%$ of high-technology firms in the US have immigrants on their founding teams (Rametse et al., 2018). Nonetheless, WEs seldom attract the same attention as men entrepreneurs, and the masculine construct of technology embedded within the high-technology sector tends to be ignored (Ahl, 2006; Wajcman, 2010).

Although immigrant WEs certainly face disadvantages, these disadvantages might differ based on their culture, race, nationality, religion, or ethnicity. If we keep the analogy of the glass ceiling, each of these disadvantages seems to add a new layer to that ceiling or thickens the existing pane of glass. For example, cultural restrictions within their communities might restrict women from reaching a public platform (Kawarazuka and Prain, 2019). Other challenges that WEs might face in their host countries 
could include discrimination and language barriers based on their country of origin (Fernando et al., 2015). Though these subtle differences among immigrants determine the barriers they face, our systematic literature review of the extant literature shows how most researchers neglect to investigate these differences.

This paper investigates the barriers faced by immigrant WEs who operate in the technology sector and their strategies to cope with these barriers. Through this literature review, two research questions are addressed: (a) What are the key challenges faced by immigrant WEs in the technology sector?; and (b) What are the key strategies adopted by them to overcome these challenges? The initial literature search showcased the paucity of literature, mainly immigrant WEs operating in the high-technology industry (Poggesi et al., 2016). Therefore, there is a need for a systematic literature review to tie diverse threads of knowledge concerning immigrant WEs, uncover limitations in existing studies and provide directions for future research to build a robust knowledge about immigrant WEs.

This study contributes to the literature in two ways. First, it bridges the literature on WEs in technology and on immigrant entrepreneurs. Through a systematic analysis of the literature, we compile dispersed knowledge. We present our findings on a three-by-two matrix reflecting the origins of the barrier or strategy (the individual, firm, or institutional level) versus the types of the barrier and strategy (being an immigrant woman and being a woman in the technology sector).

Second, this review identifies critical research gaps that could guide a research agenda for future studies. In particular, we hope our findings could encourage investigations to find out the nuanced differences among immigrant WEs arising from their culture, race, nationality, religion, or ethnicity. Even though immigrant WEs are heterogeneous groups, limited research on differences between these groups restricts research findings, focusing on the immigrant as one entity rather than discussing each layer of the glass ceiling. If future studies could unpack these differences, researchers could develop potential means of tearing down the multiple glass ceilings to empower immigrant women and support their contribution to society.

The remainder of this paper is structured as follows. The next section provides the foundation of the present review followed by the methodology section. After the methodology section, the literature review is presented. The paper analyzes previous studies that report on women's entrepreneurship and the influence on ethnic background and particular industries. The final section summarizes the findings and provides a research agenda for future work. 


\section{Gender, Immigrants and Technology}

WEs begin to gain prominence in the late 1970s (Schwartz, 1976; Poggesi et al., 2016). Studies conducted in the 1980s and 1990s are primarily limited to either understanding the characteristics of WEs and women-owned firms or identifying their differences from their male counterparts (Kalleberg and Leicht, 1991; Cromie and Birley, 1992). In the early 1990s, the focus shifted to developing theories to interpret the differences between firms led by WEs and those led by men to understand why such differences exist. Around that time, studies shifted toward taking the perspectives of social and liberal feminism into account (Fischer et al.,1993).

The literature on technology-based firms predominantly takes men as primary samples (Mayer, 2008; Dautzenberg, 2012; Hampton et al., 2011). In rare studies considering gender, the entrepreneurship literature overemphasizes the individual differences where the ideal model or the default entrepreneur corresponds to the male entrepreneur (Ahl and Marlow, 2012). For example, many studies explain the lower number of women in the technology sector by women's lack of experience in this industry, their underdeveloped managerial skills, and their negative perception (Mayer, 2006; Dautzenberg, 2012; Essers and Tedmanson, 2014). In some cases, a few studies point out some societal problems for the low participation rate of women in the high-technology sector, such as the discrimination they face in obtaining funding (Joshi et al., 2018). Furthermore, the social comparisons between WEs and their counterparts increase pressure on WEs (Kuschel, 2019), making them a target of male-dominated rules (Billing, 2011).

Nonspecific gender studies show an inclination by immigrants toward the technology sector. In one study, among high-impact technology ventures in the US, $16 \%$ of firms have an immigrant among their founders (Hart and Acs, 2011). Brown et al. (2019) show that nearly $20 \%$ of the US firms in the high technology sector have immigrant founders. Hart and Acs (2011) compare firms founded by immigrants with native-founded firms and report that the immigrant firms outperform their native counterparts in 15 of 16 dimensions of innovation. Immigrant entrepreneurs also tend to locate their businesses where there are larger immigrant populations and seek to build more strategically oriented relationships with foreign companies. McQuaid et al. (2010) suggest that immigrant entrepreneurs work to create links to their homelands to expand their business because their connections there expedite their growth.

Interest in investigating immigrant WEs only appears in the mid-2000s as researchers begin to look into different characteristics of immigrant WEs and the barriers they face due to their immigrant status (Collins and Low, 2010; McQuaid et al., 2010). Although immigrant WEs share similarities with other entrepreneurs, some differences arise due to their social and cultural aspects. For instance, the presence of women in the public eye may be treated as an offense while for men, it would be fine (Chreim et al 


\section{Approach and data collection}

This research was conducted to identify research gaps to guide future research to understand immigrant WEs operating in the technology industry. It followed Standard Preferred Reporting Items for Systematic Reviews and Meta-Analyses (Moher et al., 2009). It used the Scopus, Web of Science, and ProQuest databases, as shown in Table 1.

TABLE 1: Details about the process of SLRs

\section{A. Keywords}

We searched all three databases with the keywords provided in Table 1 . We did not use the term "businesswomen" in our searches because it did not produce useful articles beyond what other searches produced. Boolean logic was used to connect all of the keywords to the results using combinations of keywords. Immigrant status was captured using the keywords (immigrant* OR migrant* OR ethnic*) (Chreim et al., 2018), and technology-based venture studies were identified using (techno* OR hightech* OR innovat*) (Wheadon and Duval-Couetil, 2019). All keywords were used to search the title, 
abstract and keywords for all potential articles. Additionally, only English-language publications and peer-reviewed journal articles were considered.

\section{B. Selection of articles}

Because this study focused on the challenges faced by immigrant WEs and WEs leading tech-based ventures, the review had three stages. The first stage investigated articles focusing on WEs who own a tech-based venture. An initial search in all three databases identified 595 articles published between 1980 to 2020. Then, articles that focus on the challenges faced by immigrant WEs were searched, which resulted in 234 articles. The final search queried articles that report the challenges faced by immigrant WEs who own a tech-based venture. Although this produced around 50 articles, these had already been identified either in part 1 or part 2 of the analyses. Table 1 presents the distribution of the articles found in the three databases.

All of the articles were first evaluated on the title and abstract. The authors removed all duplicate articles, as shown in Figure 1. The initial elimination was done through reviewing all of the titles and abstracts and eliminating the articles which met the following criteria:

- Addresses WEs owning a business in a field other than technology or non-immigrant WEs

- Focuses on a student's or an entrepreneur's intentions or orientation

- Studies women managers, executives, board members, or in leadership roles

- Describes the use of technology by WEs

- Studies the characteristics or motivations of WEs

- Ignores the barriers faced by WEs

Many articles were removed because most researchers focus on entrepreneurial intentions or motivations or issues in women's education, paying little attention to entrepreneurial experiences. A final exclusion took place after all full-text articles were read. This exclusion eliminated articles that did not concern the technology industry, gender differentiation, migrants and those that do not examine barriers and consider WEs and ethnic entrepreneurs separately. The final result after all exclusions were accounted for included 49 articles across 31 journals. Extensive analyses of these are presented in the next section. In the final dataset, 24 articles examine immigrant WEs directly, and the remaining 25 focus on WEs leading tech-based ventures.

FIGURE 2: Selection Process 


\section{Key demographics}

Figure 2 shows an analysis of the trends in the literature derived from all articles selected for the review. The earliest article selected was published in 2005. The peak of articles looking specifically at barriers and challenges related to gender occurred in 2012. Several studies focused on different groups of WEs and identified their career barriers. Of all articles identified, 29\% are published in just three journals: International Journal of Gender and Entrepreneurship, International Journal of Entrepreneurial Behaviour and Research, and Entrepreneurship and Regional Development. Table 2 contains the top journals which publish women entrepreneurship articles. Furthermore, $84 \%$ of articles came from Business, Management and accounting, and social sciences subject areas.

FIGURE 2: Article distribution by year

Of the 49 articles in the final dataset, 41 are empirical papers, and the remaining eight are conceptual, including six review articles. Of the empirical articles, qualitative methodologies are predominant, and data collection is largely done through interviews. Only five articles use surveys to study WEs. However, researchers are aware of the limitations to generalization incumbent upon the lower samples in an interview study. Despite this limitation, these qualitative studies can help construct a theoretical foundation for the research topic that quantitative studies could later validate. In addition, a limited number of samples can enable in-depth analyses, including assessments of life history (see Marlow and McAdam, 2012), and help produce critical insights into a problem. Larger samples are more evident in quantitative studies (see McQuaid et al., 2010; Heilbrunn et al., 2014), and statistical analyses can produce generalized results.

TABLE 2: The top journals publishing on WE

All of the reviewed literature on immigrant WEs discusses immigrants from developing countries who settle in developed ones, with only one exception: Heilbrunn et al. (2014), who investigate Israel, a developing country, as the host country. Almost all papers treat immigrant status as a macro construct. Only three studies discussed the stratification of immigrants by comparing immigrant WEs from different ethnic groups (De Vries and Dana, 2012; Fielden and Davidson, 2012; Heilbrunn et al., 2014). For instance, a study finds that Indian immigrant WEs focused more on family ties and did not rely on professional services than Dutch immigrant WEs (De Vries and Dana, 2012). 


\section{Data analyses}

We placed all of the key information on the 49 articles into Microsoft Excel, including the title, abstract, year of publication, journal name, and research question for each article. To analyze the complete articles, we performed content analyses. For the content analyses, we used the qualitative data analysis software named NVivo (Kraus et al., 2020).

The first stage of content analyses included deductive coding to identify all essential information on the articles. This stage produced six broad coding categories: research objective, definitions, research methodology, findings, barriers faced by WEs, and their strategies to overcome them. Surface-level coding was performed for these six categories to extract essential information (Krippendor, 2004).

In stage two, inductive coding of the acquired data was performed. All of the coded content was subdivided, relating to similarities and differences in the data. This coding produced sub-codes for use in identifying patterns in the data, such as research methodologies, which were further divided by framework or theory, type of method, means of data collection and analysis, the number of participants, and participants' host and home country (Krippendor, 2004). A total of 290 barriers were identified in the first stage. After grouping similar barriers, 26 unique barriers were identified for immigrant WEs, and 31 were identified for WEs leading tech-based ventures. In addition, ten overlapping barriers were faced by immigrant WEs leading tech-based ventures. We further analyzed and grouped these barriers into individual-, firm-, and institutional-level barriers, as shown in Figure 3. This is because each level represents where the specific barrier occurs.

FIGURE 3: Barriers faced by WEs distributed by the level of occurrence

We are well aware that some barriers overlap. However, our study does not examine any of these casual relationships. Instead, it seeks to categorize them based on their sources and types. It is important to remember that male entrepreneur may encounter some of the barriers mentioned. However, this study limited its investigation to the perspective of WEs. Further, some barriers may only appear in a specific country or region or for a specific ethnicity and thus, may not be generalizable. However, this literature review can help to set the direction for future research.

\section{Findings: Barriers identified through analyses of the literature}

Studies on WEs have explored different areas of entrepreneurship research contributing towards building an individual entity of research, including theories and frameworks specific to WEs. Our 
review unfolds this state-of-the-art research area, by looking specifically at two particular entities of WEs, namely immigrant WEs and WEs running technology ventures. Inspired by previous studies (Adler and Izraeli, 1994; Cetindamar and Beyhan, 2019), this study categorizes the array of causes presented in the literature to explain the lower participation of immigrant women in the technology sector by individual, firm, and societal level barriers. These levels represent where barriers occur for immigrants.

Doing so can help us understand the causes that obstruct women's careers in entrepreneurship. Hence, our core research questions are (a) What are the key challenges faced by immigrant WEs in the technology sector?; and (b) What are the key strategies adopted by them to overcome these challenges? While we examine challenges, we categorize them based on their level of occurrences, namely individual, firm, and societal level. We also add two additional lenses to account for barriers specific to the technology sector and barriers arising from being an immigrant. By doing so, we offer a matrix presentation of the barriers identified from the literature in Tables 3, 4, and 5. A detailed discussion of these follows.

\section{A. Individual-level barriers}

Individual-level barriers relate to an individual's characteristics, such as education or prior work experience (Altinay and Wang, 2011). These barriers relate to all of the factors and experiences that shape an individual's perspective, including, for instance, fear of failure or lack of expertise in a specific knowledge area (Cho et al., 2019). Lack of confidence tends to restrict women from being immigrant entrepreneurs and founding a technology-based venture (Orser et al., 2012; Cho et al., 2019; Wheadon and Duval-Couetil, 2019). The following section discusses individual-level barriers specific to immigrant WEs and WEs in the technology sector.

\section{Barriers in the technology sector}

In the technology sector, gender differences at the individual level are mainly observed in human capital characteristics, such as education (Ahuja, 2002). However, it is hard to justify many personal characteristics without linking them to social context. For example, Cukier (2009) argues that women have a low level of self-efficacy in technology compared to men, which prevents them from entering engineering, technology, or computer science (Cukier, 2009). However, one study finds that women have a high likelihood of becoming technology entrepreneurs in countries with appropriate policies for women's education in science, technology, engineering, and mathematics (Dilli and Westerhuis, 2018). 
Another example is about the assertion that women are risk-avoiders while men are risk-tolerant entrepreneurs (Polkowska, 2013; Orser et al., 2019). However, WEs' risk-taking capacity might be affected by the culture that women come from (Marlow and Swail, 2014). That is why these kinds of generalisations often lead to stereotyping as well as unconscious biases about WEs.

Overall, the literature indicates that the barriers faced by women in the technology sector include lack of entrepreneurial education and skill development, lack of women investors, limited media coverage showcasing women in the technology sector, limited career guidance and lack of confidence (Orser, 2009; Polkowska, 2013; Orser et al., 2019).

\section{Barriers based on immigration status}

Rametse et al. (2018), in their study of immigrant entrepreneurs, find that, in general, immigrants seek to found ventures due to a mix of push and pull effects. Push factors that can inhibit women from founding a venture include lack of English fluency, racial discrimination, lack of recognized qualifications, and weak local work experience (Collins and Low, 2010; De Vries and Dana, 2012; Fielden and Davidson, 2012). Pull factors refer to being achievement- and goal-oriented and having a strong internal locus of control (De Vries and Dana, 2012; Rametse et al., 2018). In other words, individual-level barriers for immigrant WEs include low language fluency, lack of the knowledge and skills required to run a business, poor understanding of competition and local business culture, negative perceptions of external help, and fear of failure (Heilbrunn et al., 2014; Bastian et al., 2018; Fisher and Lewin, 2018).

TABLE 3: Type of barriers faced by women at the individual level due to their immigrant status or existence in the technology sector

\section{B. Firm-level barriers}

Firm-level barriers relate to the resource requirements for starting and running firms, including invisible industry rules and processes (Carrillo and Gromb, 2006). Women face a dearth of resources, including capital (Verheijen et al., 2014; Fisher and Lewin, 2018; Njaramba et al., 2018; Bastian et al., 2018), networks (Kwong et al., 2009; Verheijen et al., 2014; Naidu and Chand, 2017; Shukla and Chauhan, 2018), and skilled workforce (Mathew 2010). 


\section{Barriers in the technology sector}

Firm-level gender differences can be observed throughout an organization's culture, including the informal behavioral rules, procedures, and priorities of the organization, along with its incentive schemes (Carrillo and Gromb, 2006). This embedded culture creates inertia, which indirectly favors specialists (such as engineers or technical experts) over generalists (such as administrators) (Carrillo and Gromb, 2006). When organizational culture incentivizes firms to employ men in the most critical positions, women end up holding secondary roles that pay low wages, are less prestigious and offer little flexibility relative to the primary positions (Peitchinis, 1989). This culture is due to the masculinized nature of the technology sector, which has limited women's participation (Polkowska, 2013; Wajcman, 2010).

Women fail to gain management or technical experience in technology firms when women work in routine or generic roles rather than analytic or managerial jobs (Orser et al., 2007). Furthermore, there is a scarcity of woman role models that these WEs can look up to (Polkowska, 2013; Shukla and Chauhan, 2018). Such role models include not only WEs in the technology sector but also women in higher leadership roles.

Hampton et al. (2009) show how networks' roles can differ as firms grow. Before a firm is founded, WEs use networks to gather information, whereas, during the execution and operational phase of a new venture, they use them to expand their business. However, WEs struggle with discrimination and the extra time and effort required to create and foster networks for their business (Hampton et al., 2009).

Apart from networks, WEs often go through financial challenges, restricting their growth (Kuschel et al., 2017). This challenge further escalates when WEs operate in non-traditional industries (Kuschel et al., 2017). Some of the financial challenges include difficulty in getting access to start-up funds (Dhaliwal, 2007), obtaining financial loans due to lack of information (Martin and Wright, 2005), discrimination (Ezzedeen and Zikic, 2012). Thus, these financial issues restrict their survival and growth of the business, resulting in poor performance of women-run ventures as they are undercapitalized financially (Carter et al., 2007).

Although many researchers have emphasized that WEs business growth is limited, this limitation is not due to an individual's shortfall but due to "situated constraint" (Marlow and Swail, 2004, p. 84). These constraints include experience, gendered socialization, and the external environment. While individual shortfalls are more evident than group disadvantage, most of the literature focuses on the individual factor. Thus, it is essential to look at both aspects when comparing WEs' business performance. 


\section{Barriers based on immigration status}

Traditionally, most immigrant entrepreneurs begin businesses in retail or services sectors (Collins and Low, 2010; De Vries and Dana, 2012; Rametse et al., 2018). These sectors typically require low-skilled personnel and little capital investment and are perceived as not contributing substantially to the economy (McQuaid et al., 2010). As they acquire more qualifications and more significant opportunities, immigrants move toward other sectors (Rametse et al., 2018). Financial issues are encountered by all entrepreneurs (Rametse et al., 2018; Kuschel et al., 2020) and immigrants in particular. The so-called double disadvantage that immigrant women face could explain the reason for their financial difficulties (Collins and Low, 2010; De Vries and Dana, 2012).

Additionally, immigrant entrepreneurs face discrimination which demotivates immigrant entrepreneurs and escalates financial issues (Nazareno 2018). Additionally, differences have also been observed among the ethnic group for accessing financial resources. These differences are attributed to the individual's human capital and family ties (Nazareno 2018; Dabić et al., 2020).

The network is another major challenge for immigrant WEs (Collins and Low, 2010; Feilden and Davidson, 2012; Njaramba et al., 2018). Given when they arrive in the host country, immigrant WEs have a limited network. This limitation results in over-reliance on their personal network and restricts them from gaining fruitful connections within the business community, limiting their financial and business growth (Roomi, 2012). Additionally, the culture of WEs may act as a constraint to building a network. For example, Essers and Benschop (2007) report that the veil worn by Moroccan and Turkish WEs in the Netherlands symbolizes uneducated and dependent women. Also, in male-dominated cultures, such as Muslims, gender roles create a huge impact; for example, if women participate in public platforms, it is considered a "shame" for the family (Essers and Benschop, 2007). These symbolizations may build inferiority feelings among WEs, restricting their participation in networking events (Dhaliwal, 2007; Chreim et al., 2018). As a result, immigrant WEs rely more on their family network.

TABLE 4: Type of barriers faced by women at the firm level due to their immigrant status or existence in the technology sector

\section{Institutional-or societal-level barriers}

Institutional-level barriers result from the nature of the society and culture where the entrepreneurs reside (Carillo and Gromb, 2006). In any venture, rules and regulations play an essential role. Advancements in these areas can create an environment that enables women to take chances and work 
toward creating a venture. Nevertheless, WEs often face institutional-level challenges, including scant support from the government, specifically in rules, policies, and infrastructure (Naidu and Chand, 2017; Orser et al., 2019). In addition, women are often identified as homemakers, and they can be looked down on when they play the breadwinner's role (Azmat, 2013). These institutional challenges create a culture where women are considered incapable of running a business, which creates resistance from stakeholders, who refuse to support them (Ezzedeen and Zikic, 2012).

\section{Barriers in the technology sector}

Evaluating gender disparities at the institutional level highlight that the organization itself is not genderneutral, and gender differences can penetrate to the social level (Adler and Izraeli, 1994; Kawarazuka and Prain, 2019). Several studies examine the cultural biases that exist in the technology sector. Simard et al. (2008, p. 10) define the technology sector as "masculine, white and heterosexual, associated with hard programming, obsessive behavior, and extensive working hours." Gender bias in hiring, promotion, and evaluation for incentives and bonuses deter women from attaining a higher position in any organization (Simard et al., 2008; Sweida and Reichard, 2013). Further, the limited visibility of women leaders in the ICT sector and the advanced technology sector's masculine principles force WEs to create ventures mostly in female-typed industries such as retail (Hellens and Nielsen, 2001).

The entrepreneurship literature identifies the importance of family relationships for WEs and the role of networks in building and running a venture (Hampton et al., 2011). Gender differences in behavior in technology are also observed in the role that investment in families plays. Many women invest most of their effort in the household role, and men tend to invest their time in paid employment due to society expectations (Orser et al., 2012; Kirkwood and Tootell, 2008; Billore et al., 2010). A study of the American technology sector reports that men are significantly more likely to be married than women and more likely to give primary responsibility for the household and childcare to their partner (Simard et al., 2008). In sum, due to the technology sector's male-dominant nature, women tend to face societal obstacles to creating technology-based ventures in such a male-dominant institutional environment (Marlow and McAdam, 2012).

\section{Barriers based on immigration status}

Immigrant entrepreneurs have a crucial role in finding and developing technology ventures (Hart and Acs, 2011), but few studies focus on immigrant or ethnic entrepreneurs. Most of these are interested in male entrepreneurs (Collins and Low, 2010; De Vries and Dana, 2012). For example, although immigrant-founded firms are one-third of all small businesses owned by women in Australia, a gap 
remains, which explains the complexity of the issues faced by immigrant WEs relative to their male counterparts (Collins and Low, 2010).

Immigrant entrepreneurs from developing countries face many barriers when developing a business in a developed country they chose to immigrate (Azmat, 2013). These are mainly due to limited resources, discrimination, and disparities in the regulatory and legal framework between their home and host countries. Nevertheless, the host country culture might also encourage immigrants to become entrepreneurs by reducing the barriers generated by their home country culture (Verheul et al., 2002). For instance, in South Asian, Hindu, and Muslim cultures, women are generally not motivated by their families to compete with men, limiting their knowledge and access to market information (Roomi, 2013). By moving to host countries where religious boundaries, and cultural practices, and norms change, women immigrants might experience independence and mobility that could open up new career opportunities (Roomi, 2013; Dhaliwal and Kangis, 2006).

Institutional barriers tend to differ among men and women due to the cultural and social norms followed in the home country. Even among immigrant WEs from developing nations, differences are observed in their network, mainly from culture. A study by Dhaliwal et al. (2010) on South Asian WEs reported that family played a pivot role in promoting WEs by supporting them emotionally and financing their business, and pushing them to take a risk and grow their venture. Contrary to this, women from Middle Eastern and African regions pull themselves back from advancing in their careers and hence do not think of themselves as breadwinners (Dhaliwal and Kangis, 2006). These conflicts thus create challenges for some women entrepreneurs and are the reason behind the work-family conflict they face.

TABLE 5: Type of barriers faced by women at the institutional level due to their immigrant status or existence in the technology sector

\section{Strategies Used to Cope With Barriers}

WEs identify ways to respond to the challenges they face in their ventures strategically. Our analyses of the 49 selected articles categorize response strategies into similar levels to the barriers: the individual, firm-, and institutional-levels. We present all of the strategies identified in the literature in Tables 6, 7 , and 8 . 


\section{A. Individual-level response strategies}

One common strategy used by WEs is to develop or use existing skills to represent themselves as more muscular and more competitive in the field where they work (Knight, 2016; Poggesi et al., 2016; Marlow and McAdam, 2012; Azmat, 2013; Poggesi et al., 2019). For example, WEs emphasize their appearance and concentrate on projecting a professional presence through their clothing, hair, the way they communicate, and their work ethic (Marlow and McAdam, 2015; Haseki et al., 2020). Competitive entrepreneurs are expected to hold individual characteristics, such as determination, work ethic, resilience, trustworthiness, perseverance, flexibility, and professionalism (Orser et al., 2012; Martin et al., 2015; Nkrumah, 2016; Kuschel and Lepeley, 2016a; Andrejuk, 2018; Sritanyarat and Sakdiyakorn, 2020; Haseki et al., 2020). WEs try to develop and use these competitive characteristics to showcase confidence, avoid discrimination and language barriers, handle competition and avoid stereotyping.

Another response strategy is simply ignoring the barriers (Ezzedeen and Zikic, 2012; Orser et al., 2012). This strategy requires women not to focus on the negative comments or experiences but ignore them and move forward. This strategy urges women to focus on people who support their career choices and ignore those who do not (Ezzedeen and Zikic, 2012). By doing so, these WEs are moving ahead by surrounding themselves with people who are supportive of their choices.

Another strategy is to improve one's skills that might cause discrimination (Knight, 2016; Nkrumah, 2018). Because most immigrant WEs are from developing countries where English is not an official language, they make a conscious effort to speak with English-speaking individuals to improve their fluency and accent (Billore, 2011; Collier, 2011). WEs concentrate on building their skills and expertise, working nearly twice as much as men in their industry to compete equally with them (Orser et al., 2012; Ezzedeen and Zikic, 2012). Women also upskill themselves by developing resilience and determination and gaining sufficient credentials through their education and work experience (Orser $e t$ al., 2012). In addition, some WEs rely on and increase their psychological strength to overcome stereotyping and discrimination (Nkrumah, 2016).

TABLE 6: Strategies used by women at the individual level due to their immigrant status or existence in the technology sector

\section{B. Firm-level response strategies}

The primary strategy seems to be reaching out to mentors who help WEs during venture creation (Davidson et al., 2010; Orser et al., 2012; Yeganehfar et al., 2018; Poggesi et al., 2019). This strategy 
helps WEs overcome their barriers. Their mentors help WEs gain knowledge of their business and extract them from difficulties when needed (Orser et al. 2012). Their mentors provide expertise on business issues, provide psychological support, and help them reach out to their stakeholders (Orser et al., 2012; Poggesi et al., 2019).

Another common strategy used by both types of WE is to form partnerships with men, either with their spouses or family members (Dautzenberg, 2012; Martin et al., 2015; Knight, 2016; Yeganehfar et al., 2018). This strategy makes it possible to overcome gender-related barriers, including obtaining the necessary funding for the business, additional support to run it, or overcoming socio-cultural issues where women's role is conservative (Chreim et al., 2018). This strategy also increases the WEs' legitimacy and improves access to resources, particularly for WEs operating tech-based ventures (Dautzenberg, 2012). For immigrant WEs, partnering with local men increases their access to their host country resources and speeds up learning about local culture (Billore, 2011). WEs in tech-based ventures create their teams based on a solid relationship foundation. Their teams help them develop trustworthy employees who support each other (Kuschel and Lepeley, 2016b). This team spirit results in hard-working teams with a common goal of business success.

Immigrant WEs utilize their ethnic identity and culture as a response strategy to build and grow their business. For instance, some immigrant WEs use their identity to develop relationships with businesses and clients; for example, a woman from Vietnam who runs a technology business discloses her identity because of the stereotype that Asians are skilled in technology (Haseki et al., 2020). Furthermore, some immigrant WEs create their business to cater to a specific ethnic group or uses a cash-only approach to avoid documentation (Chreim et al,. 2018). Such WEs also internationalize their business by reaching out to their home country's connections, for example, obtaining supplies, marketing or technical support from their home country (Chreim et al., 2018). Internationalization also helps them save money because labor is cheaper in their home country (Chreim et al., 2018).

TABLE 7: Strategies used by women at the firm level due to their immigrant status or existence in the technology sector

\section{Institutional/societal-level response strategies}

Among the commonalities between technology WEs and immigrant WEs is the role of the family in success (Marlow and McAdam, 2012; Maitra, 2013; Rouse et al., 2013; Martin et al., 2015; Azmat and Fujimoto, 2016; Yeganehfar et al., 2018; Andrejuk, 2018; Mishra et al., 2019; Sritanyarat and Sakdiyakorn, 2020). Although family can act as a barrier by restricting WE's growth and sticking to 
women's conservative role, it acts as an enabler in many cases. Once WEs begin their venture, families support household chores, childcare, and their income as a family safety net allows them to focus on their career (Marlow and McAdam, 2012; Mishra et al., 2019). In addition to the family's emotional or motivational support, WEs use their family members in their daily business operations to obtain initial financing, connect to customers or different stakeholders, or take care of business activities (Sritanyarat and Sakdiyakorn, 2020). In addition, immigrant WEs also highlight the positive support received from other members in their ethnic group, including in finding mentors and employees, taking care of family, and building international connections for business expansion (Dhaliwal, 2007; Billore et al., 2010; Davidson et al., 2010; Maitra, 2013; Verheijen et al., 2014).

Another common strategy used by immigrant WEs is tapping into government support programs (Yeganehfar et al., 2018; Xie et al., 2018; Kalu and Okafor, 2020). Flexible government policies and regulations benefit WEs in funding or obtaining access to resources and networks or necessary entrepreneurial education (Yeganehfar et al., 2018; Kalu and Okafor, 2020).

Other institutional supports, including incubators, accelerators, or start-up hubs and communities, support WEs by providing necessary resources and capital. For instance, immigrant WEs benefit from special entrepreneurial hubs created at the ethnicity level by improving their business profile and building networks with others of the same ethnicity and culture (Vorobeva, 2019). For technology WEs, incubators and accelerators play a mediating role in facilitating their entrepreneurial careers (Xie et al., 2018); they provide them the monetary and non-monetary resources required to run the business.

Another strategy to overcome stereotyping and discrimination is to change societal expectations for women (Yeganehfar et al., 2018). Although this is time-consuming, societal change can remove discrimination and labeling barriers. For example, society can promote WEs by publicly recognizing successful WEs globally (Dhaliwal, 2007).

By adopting the strategies mentioned above, women can prevail over their challenges while running a business.

TABLE 8: Strategies used by women at the institutional level due to their immigrant status or existence in the technology sector

\section{Discussion: Mapping Out Avenues for Future Studies}

A systematic literature review can offer many advantages for scholars (Webster and Watson, 2002). Our study focuses on delivering two key benefits: presenting state-of-the-art research and inspiring 
researchers to fill the gaps identified in the entrepreneurship literature. Though this literature review we tried answering two core research questions: (a) What are the key challenges faced by immigrant WEs in the technology sector?; and (b) What are the key strategies adopted by them to overcome these challenges?

Our study compiles the dispersed knowledge on immigrant WEs operating in the technology sector. Then it presents the findings related to both the barriers they faced and their corresponding strategies to overcome these barriers. We present our findings by classifying both barriers and strategies on a three by two matrix reflecting the origins of the barrier or strategy (taking place at the individual, firm, or institutional level) versus the type of the barrier or strategy (arising from being an immigrant woman and being a woman in the technology sector). This classification is our contribution to the literature.

Although a wide variety of barriers are discussed in the literature, there is still a need to uncover topics that will reduce the gender gap, specifically in the technology field. By observing the gaps in the literature, we propose five significant avenues for future studies that could advance our knowledge on immigrant WEs operating in the technology sector.

First, future studies should investigate whether immigrant WEs starting a technology venture face the same problems as WEs venturing in other sectors. Comparative studies of this type could enrich our understanding of what factors influence immigrant WEs. Also, possible generalization of developing and developed countries as origin can showcase interesting results and pathways for future research.

Second, researchers could benefit by incorporating a theoretical lens in understanding the findings. Theories such as effectuation (Sarasvathy, 2001) and bricolage (Baker and Nelson, 2005) might help to understand entrepreneurial processes for immigrant WE. Gender stratification theory can use the present distinctions of barriers to understanding the impact of different levels on WEs (Blumberg 1988).

In addition, intersectionality theory could be instrumental in increasing our knowledge of the subtle differences among immigrant WEs. The intersectionality theory emphasizes that human experiences are shaped by a combination of factors such as nationality or gender to overcome limitations imposed by considering single factors such as age working independently (Fitzsimmonn et al., 2020). That is why the intersectionality theory could allow the observation of combinations of many factors by taking care of the context for each particular immigrant WEs. For example, this theory could also induce the implicit stratification and hierarchy of immigrant categories such as Asian versus European immigrants in a host country might experience different discrimination as observed in an Australian study (Fernando et al., 2015).

Third, most work focuses on listing the numerous barriers faced by WEs. However, a few barriers may be interlinked, such as lack of access to knowledge may lead to difficulty in starting the venture 
(Chreim et al., 2018). Future studies should examine each barrier and identify the relationships among the barriers to identify the key barriers contributing to poor performance among WEs. Moreover, ranking these barriers based on their impact can provide fruitful insights. In addition, researchers may wish to look more closely at how differences in the host country's economy change the challenges that WEs face.

Fourth, future studies should not limit themselves to identifying barriers alone but expand the investigation to observe how the literature fails to recognize society's critical role. Some studies list barriers, such as personal struggles in balancing work and family responsibilities, which indicate how factors arising from society or the culture could influence immigrant WEs (Kalu and Okafor, 2020). Taking the present study forward, researchers should examine how the three levels of barriers (individual, firm, and institutional) could affect the possible solutions and actions (education/mentoring/support, organizational/management, institutional/policy-making). Similarly, future studies could identify hierarchies among the three levels of barriers.

Last, future researchers are encouraged to conduct macro-level analyses to present a coherent framework that can account for all of the complexities present at the individual, firm, industry, and social levels. One such macro-level analysis could be to identify typical processes through which people become high-tech entrepreneurs. Alternatively, what are varied pathways that lead to the creation of a high-tech venture? Is there any difference in pathways for serial or first-time entrepreneurs? Or the role of experience in building a high-tech venture? For example, some women take the first steps into technology entrepreneurship when they are students, while some establish a technology venture after a long work experience. Observation of different pathways might help identify what steps they take and what resources and capabilities they use to overcome their barriers. Future research can also look into different characteristics possessed by WEs who were successful in creating and running the venture and comparing them with those that failed to do so. Such studies can eventually unfold WEs' attributes and move ahead from the comparison with men entrepreneurs.

In sum, we believe that studying the interaction of the three aspects of women entrepreneurship, ethnicity, and the technology sector has a lot to offer to advance each of these disciplines in an interdisciplinary way. By pursuing a stream of studies in this field, it may become possible to understand the problem's nature correctly. Conducting these studies is the first step to developing remedies at the policy level and offering sound strategies for WEs. Only then can researchers and policymakers begin working on the development of sound policy recommendations for immigrant WEs. In this way, they can initiate and support efforts to tear down the many glass ceilings they face. 


\section{Conclusions}

The present study focuses on exploring the barriers and opportunities that immigrant WEs and WEs leading technology-based ventures encounter in the form of a literature review to provide an overview of past studies and investigate the roles that gender and ethnicity play for technology firms. This literature review clearly shows an under-representation of immigrant women in the technology sector and illustrates the need for further studies.

Overall, WEs face individual-, firm-, and institutional- or societal-level barriers. The individuallevel barriers include limited fundamental and technical knowledge, lack of prior experience in the technology sector, and personal struggles in balancing work and family responsibilities. The firm-level barriers include a lack of professional networks, a lack of information about career opportunities, a lack of mentoring, and a constant battle between being a mother and an entrepreneur, combined with inadequate networking opportunities. The institutional societal barriers are the gender discrimination faced by WEs, male-dominated cultures, limitations to independence and mobility due to cultural factors, which hold back WEs in their career advancement.

In addition, immigrant status creates an additional glass ceiling. Being an immigrant escalates these problems and adds new challenges, such as a lack of language fluency and widespread discrimination against immigrants in general. Furthermore, the role of the family in balancing work and family responsibilities or in gaining support to create and run a venture is crucial for women, irrespective of their ethnic origin or their industry.

This paper also summarizes response strategies adopted by WEs to fight against the barriers they encounter. These strategies relate to the three levels of barriers. Individual-level response strategies include gaining expertise and knowledge on the business and industry, adopting masculine traits, and developing critical entrepreneurial characteristics such as perseverance and resilience. Firm-level response strategies focus on the vital business environment. These strategies include partnering with men, reaching out to networks, and finding a professional mentor/advisor. Institutional- and societallevel response strategies include seeking out the support that government, start-up agencies, and society provide to promote WEs.

Although immigrant WEs faces several disadvantages, some disadvantages may act as an enabler and help these women step up in their career. For instance, immigrant WEs can take advantage of their ethnic community in their host country and start their venture. As highlighted in past research, immigrant entrepreneurs from specific ethnic groups try to locate themselves near their community and build their business (Collins and Low, 2010; Azmat, 2013; Chreim et al., 2018). Immigrant-friendly 
policies by the host country government can also play a crucial role in getting the necessary kick-start (Kalu and Okafor, 2020). Also, lately, policies asking companies to include women as board members are helping create more role models worldwide. Thus, WEs can take advantage of such policies to create and run their businesses.

As identified in the present review of literature, although the interest of researchers in this is area is elevating, there is still limited research. Therefore, as mentioned above, numerous avenues will help unfold women's entrepreneurship literature and treat this area as a separate research field that needs more attention. Looking in-depth, the gaps identified in this review - such as multi-layered glass-ceiling formed by race, ethnicity, culture, age, or industry - would undoubtedly contribute towards expanding and enriching the knowledge about immigrant WEs in the technology sector.

\section{References}

* indicates the articles identified by the literature review method.

Acs, Z. J., Szerb, L. and Lloyd, A. (2017), “Global Entrepreneurship and Development Index 2017”, Washington DC: CreateSpace Independent Publishing Platform.

Adler, N.J. and Izraeli, D. (1994), Competitive Frontiers: Women Managers in a Global Economy, Cambridge, Blackwell, Cambridge, MA.

Ahl, H. (2006), "Why research on women entrepreneurs needs new directions", Entrepreneurship Theory and Practice, Vol. 30 No. 5, pp. 595-621.

Ahl, H. and Marlow, S. (2012), "Exploring the dynamics of gender, feminism and entrepreneurship: Advancing debate to escape a dead end?', Organization, Vol. 19 No. 5, pp. 543-562.

Ahuja, M. (2002), "Women in the information technology profession: A literature review, synthesis and research agenda", European Journal of Information Systems, Vol. 11 No. 1, pp. 20-34.

Aliaga-Isla, R., and Rialp, A. (2013), "Systematic review of immigrant entrepreneurship literature: previous findings and ways forward", Entrepreneurship and Regional Development, Vol. 25 No. 9-10, pp. 819-844.

Altinay, L., and Wang, C. L. (2011), "The influence of an entrepreneur's socio-cultural characteristics on the entrepreneurial orientation of small firms", Journal of Small Business and Enterprise Development, Vol. 18 No. 4, pp. 673-694

*Andrejuk, K. (2018), "Entrepreneurial strategies as a response to discrimination: Experience of Ukrainian women in Poland from the intersectional perspective", Anthropological Notebooks, Vol. 24 No. 2, pp. 25-40.

*Azmat, F. (2013), "Opportunities or obstacles? Understanding the challenges faced by migrant women entrepreneurs", International Journal of Gender and Entrepreneurship, Vol. 5 No. 2, pp. 198-215.

*Azmat, F., and Fujimoto, Y. (2016), "Family embeddedness and entrepreneurship experience: A study of Indian migrant women entrepreneurs in Australia", Entrepreneurship \& Regional Development, Vol. 28 No. 9-10, pp. 630-656.

Baker, T., and Nelson, R.E. (2005), "Creating something from nothing: Resource construction through entrepreneurial bricolage", Administrative Science Quarterly, Vol. 50 No. 3, pp. 329-366.

Bastian, B. L., Sidani, Y. M., and El Amine, Y. (2018), "Women entrepreneurship in the Middle East and North Africa: A review of knowledge areas and research gaps", Gender in Management: An International Journal, Vol. 33 No. 1, pp. 14-29. 
Billing, Y. D. (2011), “Are women in management victims of the phantom of the male norm?”, Gender, Work and Organization, Vol. 18 No. 3, pp. 298-317.

*Billore, S. (2011), "Female immigrant entrepreneurship", International Journal of Gender and Entrepreneurship, Vol. 3 No. 1, pp. 38-55.

*Billore, S., Zainuddin, A. H., Al-Haj, N. H. Y. Y., and Halkias, D. (2010), "Female immigrant entrepreneurship: A developing sector in Japan's entrepreneurial economy", Journal of Developmental Entrepreneurship, Vol. 15 No. 2, pp. 165-186.

Blumberg, R.L. (1988), "Income under female versus male control: hypotheses from a theory of gender stratification and data from the third world", Journal of Family Issues, Vol. 9 No. 1, pp. 51-84.

Boyd, M. (1984), "At a disadvantage: The occupational attainment of foreign-born women in Canada", International Migration Review, Vol. 18 No. 4, pp. 1091-120

Brown, D., Earle, J., Kim, M.J. and Lee, K.M. (2019), "Immigrant Entrepreneurs and Innovation in the US Hightech sector", NBER Working Paper Series.

Carrillo, J., and D. Gromb. (2006), "Cultural inertia and uniformity in organizations", Journal of Law, Economics and Organization, Vol. 23 No. 3, pp. 743-71.

Carter, S., Shaw, E., Lam, W., and Wilson, F. (2007), “Gender, entrepreneurship, and bank lending: The criteria and processes used by bank loan officers in assessing applications", Entrepreneurship Theory and Practice, Vol. 31 No. 3, pp. 427-444.

Cetindamar, D. and Beyhan, B. (2019), "Using Women entrepreneurship in technology ventures: gendered organization and gendered society interactions", in F. P. Appio, F. Therin and H. Yoon (Eds.), Handbook of Research on Techno-Entrepreneurial Ecosystems, 3rd Edition, Edward Elgar.

*Cho, E., Moon, Z. K., and Bounkhong, T. (2019), “A qualitative study on motivators and barriers affecting entrepreneurship among Latinas", Gender in Management: An International Journal, Vol. 34 No. 4, pp. 326343.

*Chreim, S., Spence, M., Crick, D., and Liao, X. (2018), "Review of female immigrant entrepreneurship research: Past findings, gaps and ways forward”, European Management Journal, Vol. 36 No. 2, pp. 210-222.

*Collier S. (2011), "Negotiating Business, Negotiating Self: Crossing Cultural Borders in Bilingual Entrepreneurial Contexts", Journal of Language, Identity, and Education, Vol. 10 No. 1, pp. 1-21

*Collins, J. and Low, A. (2010), “Asian female immigrant entrepreneurs in small and medium-sized businesses in Australia”, Entrepreneurship and Regional Development, Vol. 22 No. 1, pp. 97-111.

Cromie, S., and Birley, S. (1992), "Networking by female business owners in Northern Ireland", Journal of Business Venturing, Vol. 7 No. 3, pp. 237-251.

Cukier, W. (2009), "Attracting, retaining and promoting women. Best practices in the Canadian tech sector", In Canadian Advanced Technology Alliance Women in Tech Forum, Ottawa.

Dabić, M., Vlačić, B., Paul, J., Dana, L. P., Sahasranamam, S., and Glinka, B. (2020), "Immigrant entrepreneurship: A review and research agenda", Journal of Business Research, Vol. 113, pp. 25-38.

*Dautzenberg, K. (2012), "Gender differences of business owners in technology-based firms", International Journal of Gender and Entrepreneurship, Vol. 4 No. 1, pp. 79-98.

*Davidson, M. J., Fielden, S. L., and Omar, A. (2010), "Black, Asian and Minority Ethnic female business owners", International Journal of Entrepreneurial Behavior \& Research, Vol. 16 No. 1, pp. 58-80.

*De Vries, H.P. and Dana, T.E. (2012), "Experiences of ethnic minority immigrant women entrepreneurs in contrast to male counterparts", International Journal of Entrepreneurship and Small Business, Vol. 15 No. 4 , pp. 502-15.

Dhaliwal, S., and Kangis, P. (2006), “Asians in the UK: gender, generations and enterprise”, Equal Opportunities International, Vol. 25 No. 2, pp. 92-108. 
*Dhaliwal, S. (2007), "Dynamism and enterprise: Asian female entrepreneurs in the United Kingdom”, Journal of Immigrant \& Refugee Studies, Vol. 5 No. 2, pp. 45-64.

Dhaliwal, S., Scott, J. M., and Hussain, J. (2010), "Help or hindrance? South Asian women in the family firm", Electronic Journal of Family Business Studies, Vol. 4 No. 1, pp.5-23.

Dheer, R. J. (2018), "Entrepreneurship by immigrants: a review of existing literature and directions for future research", International Entrepreneurship and Management Journal, Vol. 14 No. 3, pp. 555-614.

Dilli, S. and Westerhuis, G. (2018), "How institutions and gender differences in education shape entrepreneurial activity: a cross-national perspective", Small Business Economics, Vol. 52 No.2, pp. 371-92.

Essers, C., and Benschop, Y. (2007), "Enterprising identities: Female entrepreneurs of Moroccan or Turkish origin in the Netherlands", Organization Studies, Vol. 28 No. 1, pp. 49-69.

*Essers, C., and Tedmanson, D. (2014), “Upsetting 'Others' in the Netherlands: Narratives of Muslim Turkish Migrant Businesswomen at the Crossroads of Ethnicity, Gender and Religion", Gender, Work and Organization, Vol. 21 No.4, pp. 353-367.

*Ezzedeen, S. R., and Zikic, J. (2012), "Entrepreneurial experiences of women in Canadian high technology", International Journal of Gender and Entrepreneurship, Vol. 4 No. 1, pp. 44-64.

Fernando, M., Almeida, S., and Dharmage, S. C. (2015), “Employer perceptions of migrant candidates' suitability: the influence of decision-maker and organisational characteristics," Asia Pacific Journal of Human Research, Vol. 54, pp. 445-464.

*Fielden, S., and Davidson, M. J. (2012), "BAME women business owners: how intersectionality affects discrimination and social support", Gender in management: An International Journal, Vol. 27 No. 8, pp. 559581.

Fisher, M., and Lewin, P. A. (2018), "Push and pull factors and Hispanic self-employment in the USA", Small Business Economics, Vol. 51 No. 4, pp. 1055-1070.

Fischer, E., Reuber, R., and Dyke, L. S. (1993), “A theoretical overview and extension of research on sex, gender, and entrepreneurship", Journal of Business Venturing, Vol. 8 No. 2, pp. 151-168.

Fitzsimmonn, S. R., Baggs, J., and Brannen, M. Y., (2020), “Intersectional arithmetic: How gender, race and mother tongue combine to impact immigrants, work outcomes," Journal of World Business, Vol. 55 No. 1. https://doi.org/10.1016/j.jwb.2019.101013

Global Entrepreneurship Monitor (GEM) (2019). 2018/2019 Women's Entrepreneurship Report

Global Entrepreneurship Research Association (GERA) (2016). Global Entrepreneurship Monitor 2016/17.

*Hampton, A., Cooper, S. and McGowan, P. (2009), "Female entrepreneurial networks and networking activity in technology-based ventures: An exploratory study", International Small Business Journal, Vol. 27 No. 2 , pp. 193-214.

*Hampton, A., McGowan, P. and Cooper, S. (2011), "Developing quality in female high-technology entrepreneurs' networks", International Journal of Entrepreneurial Behavior \& Research, Vol. 17 No. 6, pp. 588-606.

Hart, D.M. and Acs, Z.J. (2011), "High-tech immigrant entrepreneurship in the United States", Economic Development Quarterly, Vol. 25 No. 2, pp. 116-29.

*Haseki, M., Scott, C. R., and Gailliard, B. M. (2020), “Communicatively Managing Multiple, Intersecting Identities Among Immigrant Women Entrepreneurs", International Journal of Business Communication, doi: $10.1177 / 2329488420907139$.

*Heilbrunn, S., Abu-Asbeh, K., and Abu Nasra, M. (2014), "Difficulties facing women entrepreneurs in Israel: a social stratification approach", International Journal of Gender and Entrepreneurship, Vol. 6 No. 2, pp. 142162.

Hellens, L., and S. Nielen. (2001), “Australian women in IT”, Communications of the ACM, Vol. 44 No. 7, pp. 4452. 
Joshi, A. M., Inouye, T. M., and Robinson, J. A. (2018), "How does agency workforce diversity influence Federal R\&D funding of minority and women technology entrepreneurs? An analysis of the SBIR and STTR programs, 2001-2011”, Small Business Economics, Vol. 50 No. 3, pp. 499-519.

Kalleberg, A., and Leicht, K. (1991), “Gender and organizational performance: determinants of small business survival and success”, Academy of Management Journal, Vol. 34 No. 1, pp. 136-161.

*Kalu, K., and Okafor, O. N. (2020), "Programming for Immigrant Women in Canada: Is Entrepreneurship Neglected?", International Migration.

Kawarazuka, N., and Prain, G. (2019), "Gendered processes of agricultural innovation in the Northern uplands of Vietnam”, International Journal of Gender and Entrepreneurship, Vol. 11 No. 3, pp. 210-226.

Kirkwood, J., and Tootell, B. (2008), “Is entrepreneurship the answer to achieving work-family balance?", Journal of Management and Organization, Vol. 14 No. 3, pp. 285-302.

*Knight, M. (2016), "Raceing, classing and gendering racialized women's participation in entrepreneurship", Gender, Work \& Organization, Vol. 23 No. 3, pp. 310-327.

Kraus, S., Breier, M., and Dasí-Rodríguez, S. (2020), "The art of crafting a systematic literature review in entrepreneurship research", International Entrepreneurship and Management Journal, Vol. 16 No. 1 , pp. 1023-1042.

Krippendorff,K. (2004), Content Analysis: An Introduction to Its Methodology. Thousand Oaks, CA: Sage.

*Kuschel, K. (2019), "Women Founders in the Technology Industry: The Startup-Relatedness of the Decision to Become a Mother”, Administrative Sciences, Vol. 9 No. 2, pp. 30-47.

*Kuschel, K., Ettl, K., Díaz-García, C., and Alsos, G. A. (2020), "Stemming the gender gap in STEM entrepreneurship-insights into women's entrepreneurship in science, technology, engineering and mathematics", International Entrepreneurship and Management Journal, pp. 1-15.

*Kuschel, K., and Lepeley, M. T. (2016a), "Copreneurial women in start-ups", Academia Revista Latinoamericana de Administración, Vol. 29 No. 2, pp. 181-197.

*Kuschel, K., and Lepeley, M. T. (2016b), "Women start-ups in technology: Literature review and research agenda to improve participation”, International Journal of Entrepreneurship and Small Business, Vol. 27 No. 2-3, pp. 333-346.

*Kuschel, K., Lepeley, M. T., Espinosa, F., and Gutiérrez, S. (2017), "Funding challenges of Latin American women start-up founders in the technology industry", Cross Cultural \& Strategic Management, Vol. 24 No. 2 , pp. 310-331.

Kwong, C. C., Thompson, P., Jones-Evans, D., and Brooksbank, D. (2009), "Nascent entrepreneurial activity within female ethnic minority groups", International Journal of Entrepreneurial Behavior and Research, Vol. 15 No. 3, pp. 262-281.

*Maitra, S. (2013), "Points of entry: South Asian immigrant women's entry into enclave entrepreneurship in Toronto", South Asian Diaspora, Vol. 5 No. 1, pp. 123-137.

*Marlow, S. and McAdam, M. (2012), “Analyzing the Influence of Gender Upon High-Technology Venturing Within the Context of Business Incubation", Entrepreneurship: Theory and Practice, Vol. 36 No. 4, pp. 65576.

*Marlow, S., and McAdam, M. (2015). "Incubation or induction? Gendered identity work in the context of technology business incubation”, Entrepreneurship Theory and Practice, Vol. 39 No. 4, pp. 791-816.

Marlow, S., and Patton, D. (2005). All credit to men? Entrepreneurship, finance, and gender. Entrepreneurship theory and practice, Vol. 29 No. 6, pp. 717-735.

Marlow, S. and Swail, J. (2014). “Gender, risk and finance: why can't a women be more like a man?", Entrepreneurship and Regional Development, Vol. 25 No. 1/2, pp. 80-96.

*Martin, L. M., and Wright, L. T. (2005), “No gender in cyberspace?”, International Journal of Entrepreneurial Behavior \& Research, Vol. 11 No. 2, pp. 162-178. 
*Martin, L. M., Wright, L., Beaven, Z., and Matlay, H. (2015), “An unusual job for a woman? Female entrepreneurs in scientific, engineering and technology sectors", International Journal of Entrepreneurial Behavior \& Research, Vol. 21 No. 4, pp. 539-556.

Mason, C., and Brown, R. (2014), "Entrepreneurial ecosystems and growth-oriented entrepreneurship”, Paris: Final Report to OECD.

Mathew, V. (2010), "Women entrepreneurship in Middle East: Understanding barriers and use of ICT for entrepreneurship development", International Entrepreneurship and Management Journal, Vol. 6 No. 2, pp. 163-181.

Mattis, M. (2004), "Women entrepreneurs: out from under the glass ceiling", Women in Management Review, Vol. 19 No. 3, pp. 154-163.

Mayer, H. (2006), "Economic trends and location patterns of women high-tech entrepreneurs", Frontiers of entrepreneurship research, Vol. 26 No. 11, pp. 1-13.

*Mayer, H. (2008), "Segmentation and segregation patterns of women-owned high-tech firms in four metropolitan regions in the United States", Regional Studies, Vol. 42 No. 10, pp. 1357-1383.

*McQuaid, J., Smith-Doerr, L. and Monti Jr, DJ (2010), “Expanding entrepreneurship: Female and foreign-born founders of New England biotechnology firm", American Behavioral Scientist, Vol. 53 No. 7, pp. 1045-63.

Mestres, J. (2010). Migrant entrepreneurship in OECD countries and its contribution to employment.

*Mishra, D., Satpathy I., and Patnaik, B.C. M. (2019), "Role Conflict Among Women Entrepreneurs in Information Technology (IT) Sector", International Journal of Innovative Technology and Exploring Engineering, Vol. 8 No. 12, pp. 2169-2174.

Moher, D., Liberati, A., Tetzlaff, J., and Altman, D. G. (2009), "Preferred reporting items for systematic reviews and meta-analyses: The PRISMA statement”, Annals of Internal Medicine, Vol. 151 No. 4, pp. 264-9.

Naidu, S., and Chand, A. (2017), "National culture, gender inequality and women's success in micro, small and medium enterprises", Social Indicators Research, Vol. 130 No. 2, pp. 647-664.

*Nazareno, J. (2018), "Welfare state replacements: deinstitutionalization, privatization and the outsourcing to Immigrant Women Enterprise”, International Journal of Health Services, Vol. 48 No. 2, pp. 247-266.

*Njaramba, J., Chigeza, P., and Whitehouse, H. (2018), "Barriers and challenges experienced by migrant African women entrepreneurs in North Queensland, Australia", Entrepreneurship and Sustainability Issues, Entrepreneurship and Sustainability Center, Vol. 5 No. 4, pp.1054 - 1068.

*Nkrumah, A. (2016), "Ghanaian female immigrant entrepreneurs in Canada: Experiences, challenges, and coping strategies”, Open Journal of Social Sciences, Vol. 4 No. 10, pp. 59-78.

Orser, B. (2009), “Showcasing women's leadership in Canada's advanced technology sectors. Strategies to grow Canadian technology-based firms", In Canadian Advanced Technology Alliance Women in Tech Forum, Ottawa.

Orser, B., M. Cedzenski, and R. Thomas. (2007), "Modelling owner experience: Linking theory and practice", Journal of Small Business and Entrepreneurship, Vol. 20 No. 3, pp. 387-408.

*Orser, B., Riding, A. and Stanley, J., (2012), "Perceived career challenges and response strategies of women in the advanced technology sector", Entrepreneurship and Regional Development, Vol. 24 No. 1-2, pp. 73-93.

Orser, B., Riding, A., and Li, Y. (2019), “Technology adoption and gender-inclusive entrepreneurship education and training", International Journal of Gender and Entrepreneurship.

Peitchinis, S.G. (1989). Women at work: Discrimination and response. Toronto: McClelland and Stewart.

Poggesi, S., Mari, M., and De Vita, L. (2016), "What's new in female entrepreneurship research? Answers from the literature", International Entrepreneurship and Management Journal, Vol. 12 No. 3, pp. 735-764.

*Poggesi, S., Mari, M., De Vita, L., and Foss, L. (2019), "Women entrepreneurship in STEM fields: literature review and future research avenues", International Entrepreneurship and Management Journal, Vol. 16 No. 1 , pp. 17-41. 
*Polkowska, D. (2013), "Women scientists in the leaking pipeline: barriers to the commercialisation of scientific knowledge by women”, Journal of Technology Management and Innovation, Vol. 8 No. 2, pp. 156-165.

Rametse, N., Moremong-Nganunu, T., Ding, M.J. and Arenius, P. (2018), "Entrepreneurial Motivations and Capabilities of Migrant Entrepreneurs in Australia”, International Migration, Vol. 56 No. 4, pp. 217-34.

Roomi, M.A. (2013), "Entrepreneurial capital, social values and cultural traditions: exploring the growth of women-owned enterprises in Pakistan”, International Small Business Journal, Vol. 31 No. 2, pp. 175-191.

*Rouse, J., Treanor, L., Fleck, E., and Forson, C. (2013), “Contextualising migrant black business women's worklife balance experiences", International Journal of Entrepreneurial Behaviour \& Research, Vol. 19 No. 5 , pp. 460-477.

Roztocki, N. and Weistroffer, H. R. (2009), "Research trends in information and communications technology in developing, emerging and transition economies", Collegium of Economic Analysis, Vol. 20, pp. 113-127.

Sarasvathy, S.D. (2001), “Causation and effectuation: Towards a theoretical shift from economic inevitability to entrepreneurial contingency", Academy of Management Review, Vol. 26 No. 2, pp. 243-288.

Schwartz, E. (1976), "Entrepreneurship: a new female frontier”, Journal of Contemporary Business, Vol. 5 No. 1 , pp. $47-76$.

Sharafizad, J., and Coetzer, A. (2017), "Women business owners' start-up motivations and network structure", Journal of Management and Organization, Vol. 23 No. 2, pp. 206-223.

*Shukla, T., and Chauhan, G. S. (2018), "Traversing the women entrepreneurship in South Asia: A journey of Indian start-ups through Lucite ceiling phenomenon", Journal of Enterprising Communities: People and Places in the Global Economy, Vol. 12 No. 1, pp. 50-66.

Simard, C., A.D. Henderson, S. Gilmartin, L. Schiebinger, and T. Whitney (2008). Climbing the technical ladder: Obstacles and solutions for mid-level women in technology. Boulder, CO: National Center for Women and Information Technology, University of Colorado.

*Sritanyarat, D., and Sakdiyakorn, M. (2020), "Vicarious Learning from Innovative Women Entrepreneurs in Thailand", Advances in Developing Human Resources, Vol. 22 No. 2, pp. 201-214.

Sweida, G. L., and Reichard, R. J. (2013), “Gender stereotyping effects on entrepreneurial self-efficacy and highgrowth entrepreneurial intention”, Journal of Small Business and Enterprise Development, Vol. 20 No. 2, pp. 296-313.

UN (2019). United Nations, Department of Economic and Social Affairs, Population Division (2019). International Migration 2019: Wall Chart (ST/ESA/SER/A/431).

*Verheijen, V. W., Nguyen, H., and Chin, B. (2014), “The making of ethnic migrant women entrepreneurs in New Zealand”, International Journal of Entrepreneurship and Small Business, Vol. 23 No. 3, pp. $296-312$.

Verheul, I., Wennekers, S., Audretsch, D., and Thurik, R. (2002). An eclectic theory of entrepreneurship: policies, institutions and culture. In Entrepreneurship: Determinants and policy in a European-US comparison (pp. 1181). Springer, Boston, MA.

*Vorobeva, E. (2019), “Intersectionality and Policy-Making”, Politeja, Vol. 16 No. 6, pp. 139-151.

Wajcman, J. (2010), "Feminist theories of technology”, Cambridge Journal of Economics, Vol. 34 No. 1, pp. 143152.

Webster, J., and Watson, R.T. (2002), “Analyzing the past to prepare for the future”, MIS Quarterly, Vol. 26 No. 2, pp. 13-23.

*Wheadon, M., and Duval-Couetil, N. (2019), "Token entrepreneurs: a review of gender, capital, and context in technology entrepreneurship", Entrepreneurship and Regional Development, Vol. 31 No. 3-4, pp. 308-336.

*Xie, X., and Lv, J. (2018), "Female technology entrepreneurs: Resource shortages and reputation challenges-A view of institutional support", International Entrepreneurship and Management Journal, Vol. 14 No. 2 , pp. 379-403. 
*Yeganehfar, M., Zarei, A., Isfandyari-Mogghadam, A. R., and Famil-Rouhani, A. (2018), "Justice in technology policy: A systematic review of gender divide literature and the marginal contribution of women on ICT", Journal of Information, Communication and Ethics in Society, Vol. 16 No. 2, pp. 123-137. 
Table 1: Details about the process of SLRs

\begin{tabular}{|l|l|l|}
\hline Feature & Tech WE & Immigrant WE \\
\hline Research question & $\begin{array}{l}\text { techno* OR high-tech* OR } \\
\text { innovat* OR "STEM" OR } \\
\text { women OR woman OR female* OR } \\
\text { gender* OR } \\
\text { entrepreneur* OR venture* OR } \\
\text { start-up OR startup* OR business* } \\
\text { OR } \\
\text { barrier* OR obstacle* OR } \\
\text { challenge* OR problem* }\end{array}$ & $\begin{array}{l}\text { immigrant* OR migrant* OR } \\
\text { ethnic* OR } \\
\text { women OR woman OR female* } \\
\text { OR gender* OR } \\
\text { entrepreneur* OR venture* OR } \\
\text { start-up OR startup* OR } \\
\text { business* OR } \\
\text { barrier* OR obstacle* OR } \\
\text { challenge* OR problem* }\end{array}$ \\
\hline $\begin{array}{l}\text { \# of studies retrieved } \\
\text { Limited to: } \\
\text { - Journal article } \\
\text { - English language } \\
\text { - All years to 2020* }\end{array}$ & \multicolumn{2}{|c|}{$\begin{array}{c}91 \text { (Scopus) + 73 (ProQuest) + 70 } \\
\text { (WoS) }=234\end{array}$} \\
\hline
\end{tabular}

Table 2: The top journals publishing on WE

\begin{tabular}{|l|r|r|}
\hline \multicolumn{1}{|c|}{ Journal Name } & \multicolumn{1}{c|}{$\begin{array}{c}\text { No. of } \\
\text { articles }\end{array}$} & \multicolumn{1}{c|}{$\begin{array}{c}\text { Percent of } \\
\text { articles }\end{array}$} \\
\hline International Journal of Gender and Entrepreneurship & 5 & 10 \\
\hline International Journal of Entrepreneurial Behaviour and Research & 4 & 8 \\
\hline International Entrepreneurship and Management Journal & 3 & 6 \\
\hline International Journal of Entrepreneurship and Small Business & 3 & 4 \\
\hline Advances in Developing Human Resources & 2 & 4 \\
\hline Entrepreneurship and Regional Development & 2 & 4 \\
\hline Entrepreneurship: Theory and Practice & 2 & 4 \\
\hline Entrepreneurship \& Regional Development & 2 & 4 \\
\hline Gender, Work and Organization & 2 & 6 \\
\hline
\end{tabular}


Table 3. Type of barriers faced by women at the individual level due to their immigrant status or existence in the technology sector

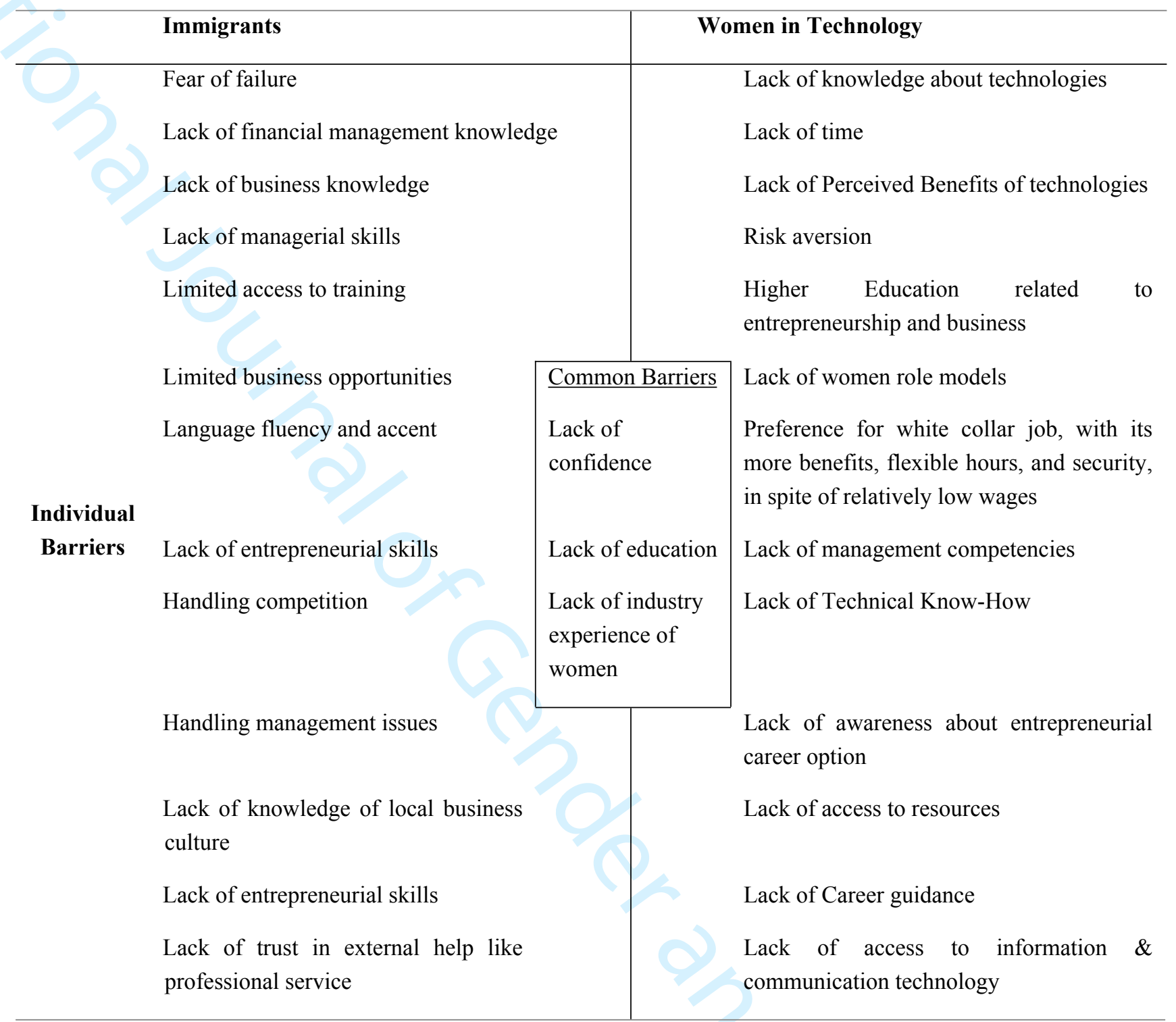

Table 4. Type of barriers faced by women at the firm level due to their immigrant status or existence in the technology sector

\begin{tabular}{|c|c|c|c|}
\hline & \multicolumn{2}{|l|}{ Immigrants } & Women in Technology \\
\hline $\begin{array}{c}\text { Firm-level } \\
\text { Barriers }\end{array}$ & $\begin{array}{l}\text { Lack of technical training } \\
\text { Expensive bureaucratic } \\
\text { processes } \\
\text { Financial pressure \& cash flow- } \\
\text { challenge }\end{array}$ & $\begin{array}{l}\text { Common Barriers } \\
\text { Lack of access to financial } \\
\text { capital } \\
\text { Lack of access to network } \\
\text { both formal and informal } \\
\text { Lack of skilled workers }\end{array}$ & $\begin{array}{l}\text { Lack of available advisor } \\
\text { Lack of credit and extension } \\
\text { services }\end{array}$ \\
\hline
\end{tabular}


Table 5. Type of barriers faced by women at the institutional level due to their immigrant status or existence in the technology sector

\section{Institutional-}

Labour market discrimination

level

\section{Barriers Gender biases}

Racial discrimination
Ethnic stereotyping

\begin{tabular}{|l|l} 
Women in Technology & Wog
\end{tabular}

Inadequate support from ethnic group

Challenges due to religious belief$$
\text { Inadequate support from }
$$
the government in terms of policies, infrastructure Societal work-family balance expectations Lack of family support Resistance from the stakeholders: financers, clients, subordinates
Negative perception of women towards technologically capable

Shortages of women in leadership roles in the ICT sector

Feminization of some fields of science which leaves limited women in commercialized science area

Industry volatility, the pace of change as well as the requisite hours and travel

Intensive competition

Accessibility to support service

Formal political rights for women

Long working hours

Pressure to adapt male principles to show authority

Gender stereotype due to presence of more men in specific industry

Entrepreneurship field mostly dominated by men

Undermining the quality of girls' education

Household structure 
Table 7. Strategies used by women at the firm level due to their immigrant status or existence in the

Individual

Strategies Self-confidence

Professionalism-dressing, communication and work ethic Psychological strength

Determination

Friendly

\section{Women in Technology}

using feminine charm

Change one's behaviour

attention to detail and strong interpersonal skills

perseverance

traits

Resilience, flexibility, Knowledge and expertise in the field open mindedness Ignoring the barriers presenting a credible professional presence

Self-learning and self-reflection

Work Harder

Focussing on supportive people technology sector

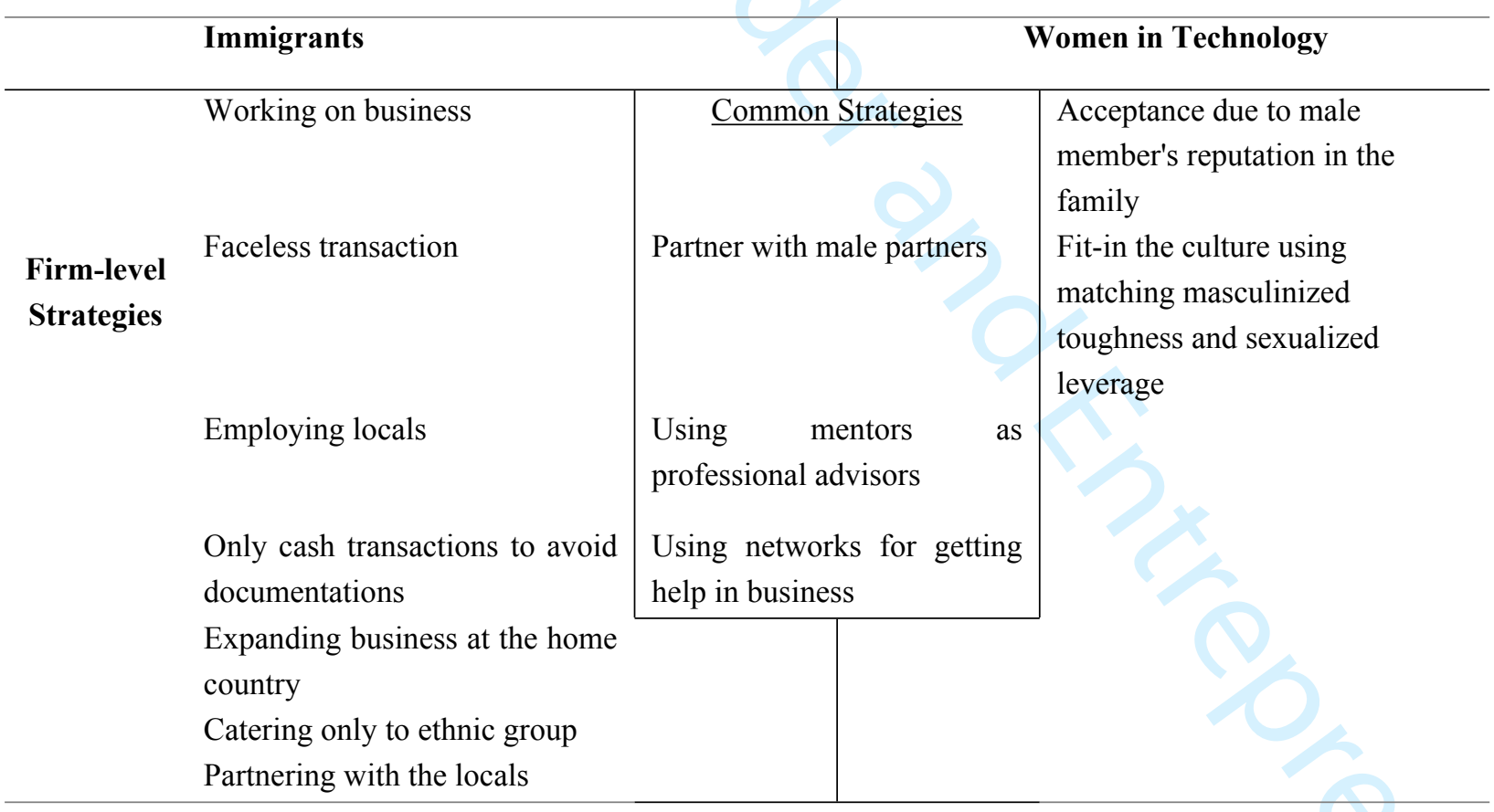


Table 8. Strategies used by women at the institutional level due to their immigrant status or existence in the technology sector

\begin{tabular}{|c|c|c|c|}
\hline \multicolumn{2}{|r|}{ Immigrants } & \multicolumn{2}{|c|}{ Women in Technology } \\
\hline $\begin{array}{c}\text { Institutional- } \\
\text { level } \\
\text { Strategies }\end{array}$ & $\begin{array}{l}\text { Support from Co-ethnic group } \\
\text { Taking help from } \\
\text { family for childcare } \\
\text { Hiring house help } \\
\text { Making spouse realise the } \\
\text { economic importance of their } \\
\text { work } \\
\text { Improving profile of WE } \\
\text { entrepreneurship hub based on } \\
\text { ethnicity } \\
\text { Language training }\end{array}$ & $\begin{array}{l}\text { Common Strategies } \\
\text { Family Support } \\
\text { Support from government } \\
\text { Designing policies to } \\
\text { increase participation of } \\
\text { WE }\end{array}$ & $\begin{array}{l}\text { Second family income as safety net } \\
\text { Spouse's support help to reduce role } \\
\text { conflict. } \\
\text { Institutional support helping to get } \\
\text { access to resources and improve WE } \\
\text { reputation } \\
\text { Change in expectations and society }\end{array}$ \\
\hline
\end{tabular}




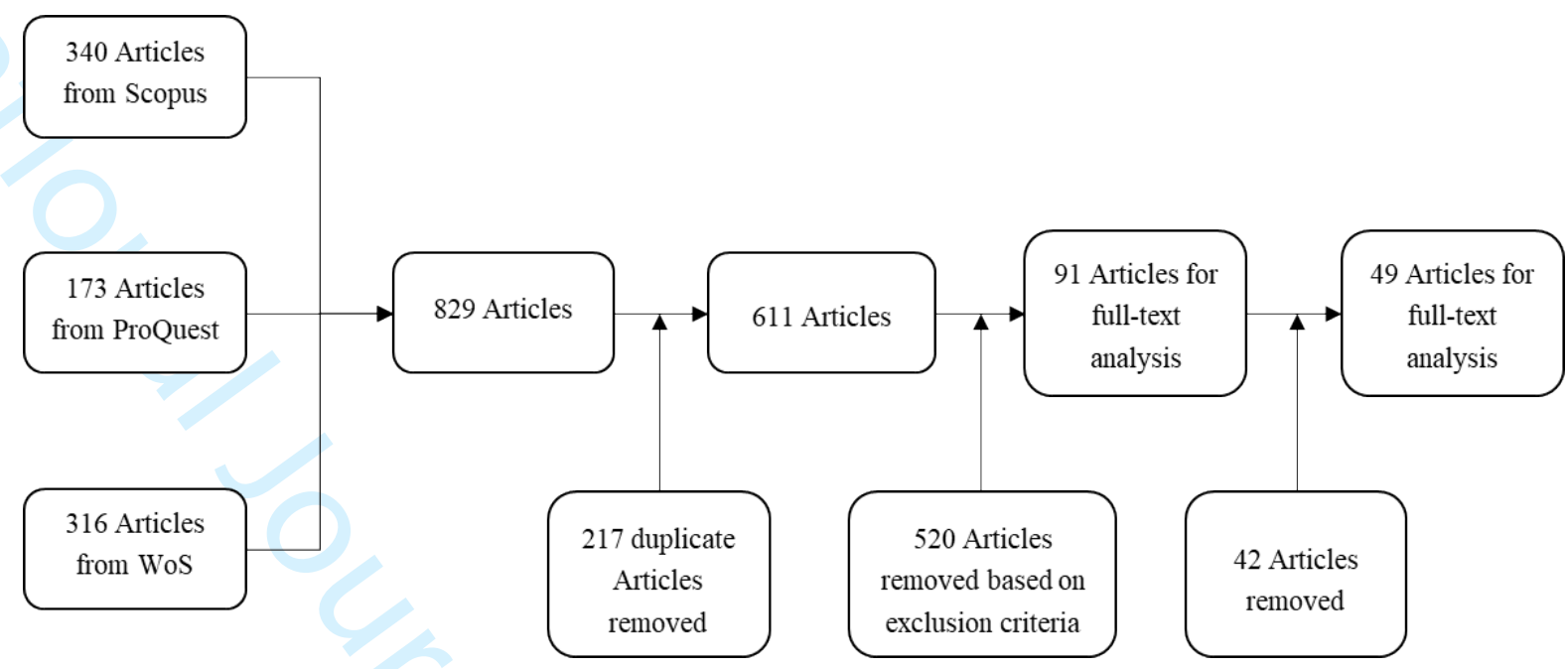

Figure 1: Selection Process

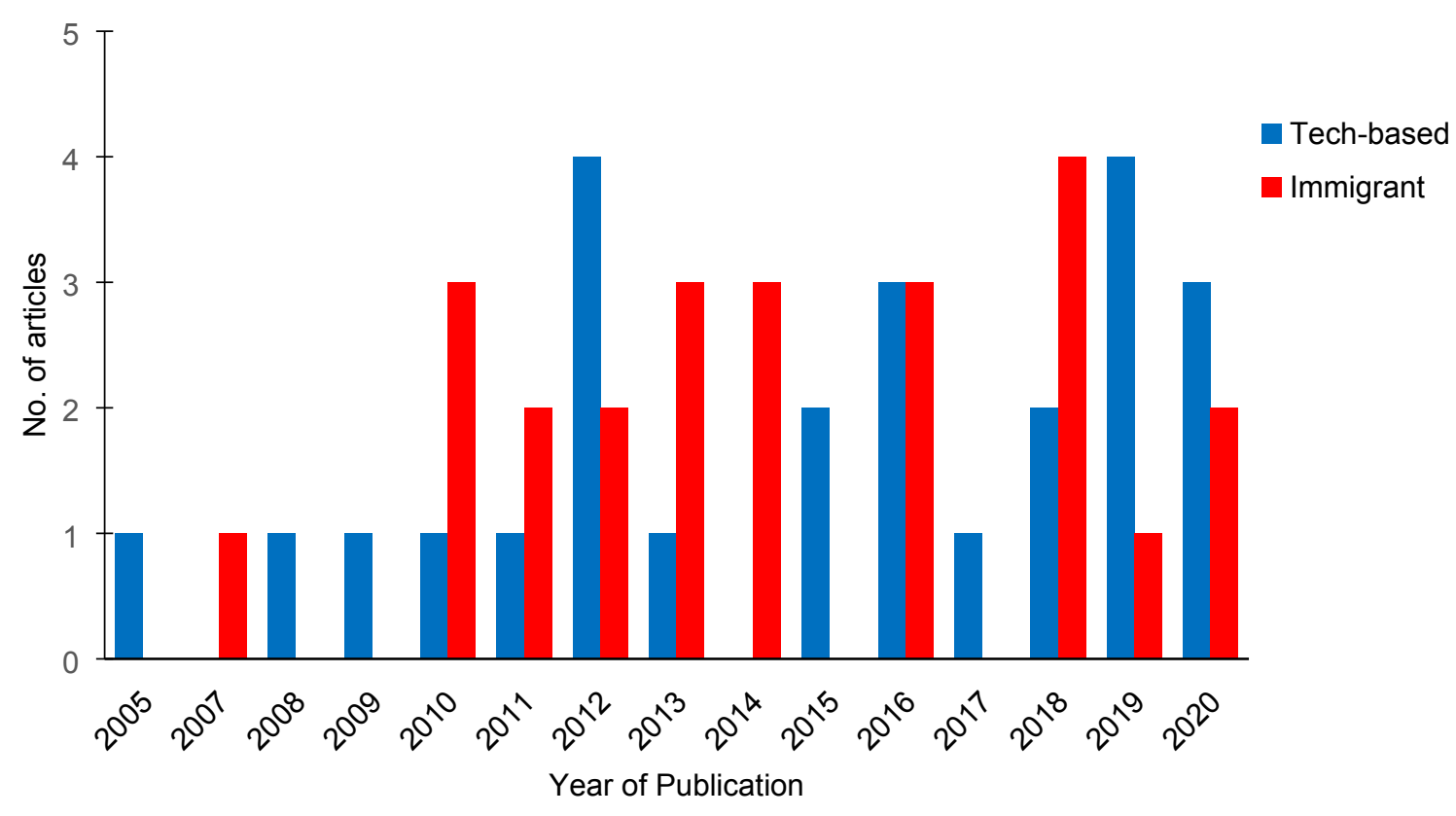

Figure 2: Article distribution by year 
Institutional level

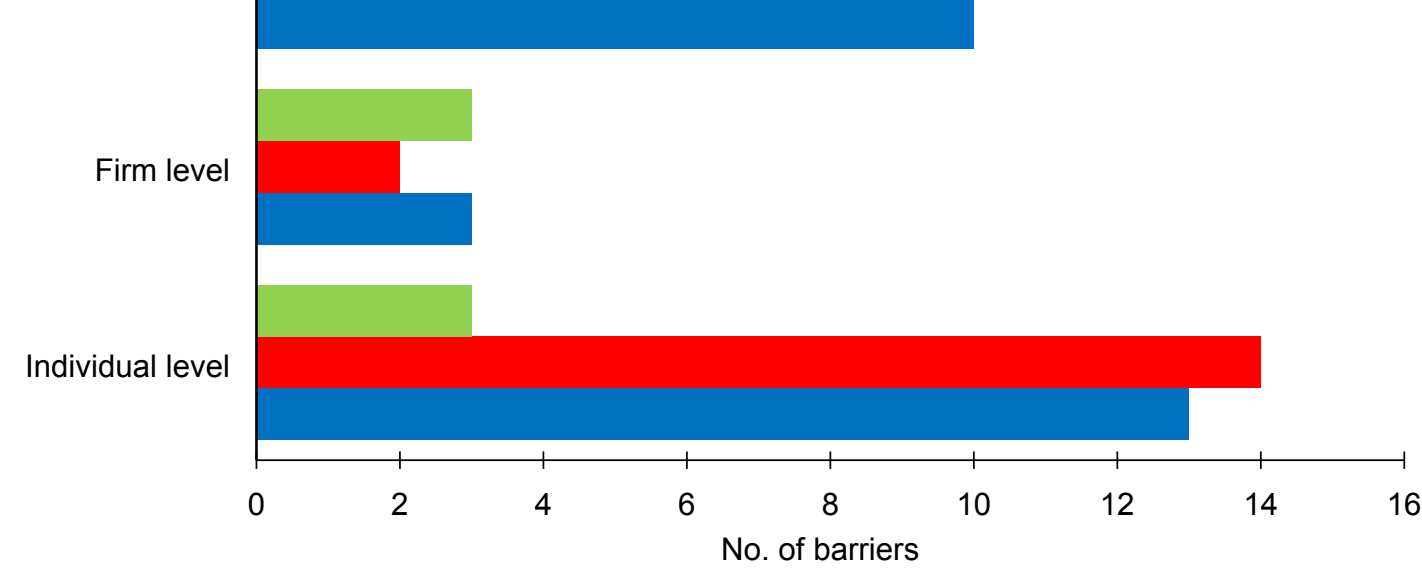

Common $\square$ Tech-based Immigrant

Figure 3: Barriers faced by WE distributed by level of occurrence 